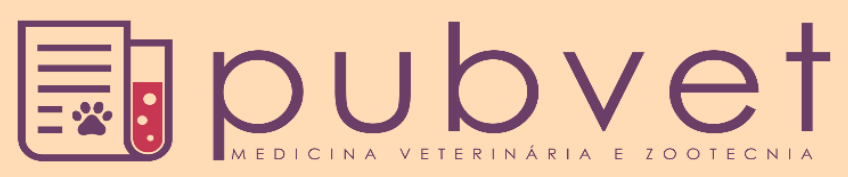

https://doi.org/10.31533/pubvet.v16n01a1023.1-5

\title{
Retalho de padrão axial em região facial de um canino: Relato de caso
}

\author{
Natarsha de Aguiar Freire ${ }^{1^{*}}$, André Rebelo Pantoja ${ }^{2} \bullet$, Dejane Neves Linhares ${ }^{3 \bullet}$ \\ ${ }^{1}$ Acadêmica do curso de Medicina Veterinária da Universidade da Amazônia, Santarém - Pará, Brasil. \\ ${ }^{2}$ Professor do Curso de Medicina Vetrinária da Universidade da Amazônia Mestre em Saúde animal, Santarém-Pará, Brasil. \\ ${ }^{3}$ Médica Veterinária, com Especialização em Clinica de Pequenos Animais. UFERSA, Santarém - Pará, Brasil. \\ *Autor para correspondência: E-mail: natarshaaguiar96@gmail.com
}

\begin{abstract}
Resumo. As cirurgias reconstrutivas, têm como objetivo à busca de resultados de forma a beneficiar animais com traumas em sua anatomia, fazendo a correção de disfunções ou perdas, seja sensitiva ou motor pela utilização de retalhos, enxertos e/ou biomateriais; quando fechamento de forma primária não é possível devido ao excesso de tensão. $\mathrm{O}$ procedimento exige do profissional experiência técnica em todo o processo, desde a escolha da técnica a ser emprega e no acompanhamento pré e pós-operatório, assim evitando complicações ou custos desnecessários. Os fatores específicos a serem avaliados iniciamse na localização da lesão e a extensão desta no corpo do animal, abrangendo região óssea ou tendões, grau de contaminação devido ao tempo de exposição, quantidade sanguínea disponível e por último a quantidade de pele e a elasticidade para o fechamento. Desta forma, objetivo deste trabalho é descrever um relato de um procedimento de cirurgia reconstrutiva em padrão axial em região facial de um canino. $O$ retalho de padrão axial omocervical se mostrou um modelo excelente para reconstrução de grandes defeitos em região de face lateral. O planejamento cirúrgico, a conduta transoperatória e o manejo pósoperatório instituído contribuíram para um pós-operatório de sucesso, com uma boa recuperação do paciente e sem complicações, sendo atualmente um animal saudável.
\end{abstract}

Palavras chave: Cirurgia reconstrutiva, qualidade de vida, bem-estar, trauma

\section{Axial pattern flap in the facial region of a canine: Case report}

\begin{abstract}
Reconstructive surgeries aim to seek results in order to benefit animals with trauma to their anatomy, correcting dysfunctions or losses, whether sensory or motor, through the use of flaps, grafts and/or biomaterials; when primary way closing is not possible due to excess tension. The procedure requires technical experience from the professional throughout the process, from the choice of the technique to be used and in the pre- and postoperative follow-up, thus avoiding unnecessary complications or costs. The specific factors to be evaluated start with the location of the lesion and its extension in the animal's body, including bone or tendons, degree of contamination due to exposure time, amount of blood available and finally the amount of skin and elasticity for closing. Thus, the objective of this paper is to describe a report of a reconstructive surgery procedure in axial pattern in the facial region of a canine. The omocervical axial pattern flap proved to be an excellent model for the reconstruction of large defects in the lateral face region. Surgical planning, intraoperative conduct and established postoperative management contributed to a successful postoperative period, with a good recovery of the patient and without complications, currently being a healthy animal.
\end{abstract}

Keywords: Reconstructive surgeries, quality of life, well-being, trauma 


\section{Introdução}

Cirurgia reconstrutiva trata-se do uso de procedimentos para corrigir anormalidadesAdivisão de cirurgia plástica é dada entre plástica estética cosmética, reparadora ou reconstrutiva (Angeli et al., 2006).

Antes da tomada de decisão da técnica a ser utilizada devem ser consideradas informações importantes como. Por exemplo, local da ferida, disponibilidade de pele e extensão das linhas de tensão (Fossum, 2014). Portanto, cabe ao cirurgião habilidade, flexibilidade e domínio técnico e científico da anatomia tempo da exposição da ferida junto à avaliação do grau de contaminação do paciente, disponibilidade de suprimento sanguíneo da aérea acometida, bem como a elasticidade tecidual para as

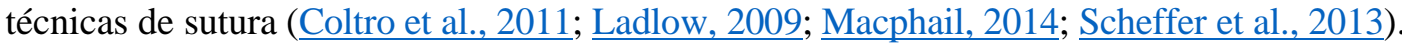

O objetivo deste trabalho é descrever um relato de um procedimento de cirurgia reconstrutiva em padrão axial em região facial de um canino.

\section{Relato de caso}

Foi atendido em uma clínica particular no município de Santarém-PA, um canino sem raça definida (SRD) com idade não informada, não castrado, de nome Marley, pesando 14,3 kg. O animal veio encaminhado do centro de controle de zoonoses para internamento e avaliação, após ter sido resgatado da rua.

Durante o exame físico ao qual o animal foi submetido, foi constatado escore corporal magro, com pelos opacos, áreas de descamações. Na região de face havia extensa ferida com perda parcial de ossos nasais e ponte nasal e perda total do focinho (Figura 1), presença de miíase, áreas de necrose e áreas de ulceração na ponte nasal esua lateral.

Nos exames laboratoriais foram solicitados hemograma e exame de Leishmaniose. Foi constatado no hemograma que o animal apresenta anemia normocítica regenerativa, leucocitose com neutrofilia, monocitose e no exame de Leishmaniose o reagente testou positivo para a doença.

Para o procedimento cirúrgico, no dia 12 de março de 2021, foi solicitado, que o paciente comparecesse a clínica, em jejum alimentar de oito horas e hídrico de seis horas. Como protocolo de medicamento pré-anestésico (MPA), utilizou-se cetamina $1 \%(5 \mathrm{mg} / \mathrm{kg})$, midazolam $(1,0 \mathrm{mg} / \mathrm{kg})$ e metadona $(0,3 \mathrm{mg} / \mathrm{kg})$, pela via intramuscular. Indução de propofol $(2,5 \mathrm{mg} / \mathrm{kg})$, também por via intravenosa, manutenção com isuflorano (por infusão contínua) por via inalatória.

No transoperatório foram utilizados cetamina $1 \%(5 \mathrm{mg} / \mathrm{kg})$ e infusão contínua de fentanil. Foi realizado o bloqueio no nervo infraorbitário com bupivacaina $(5 \mathrm{mg} / \mathrm{mL})$. Em seguida à aplicação da MPA, foi realizado acesso venoso, na veia cefálica, para fluidoterapia, realizada com solução de ringer lactato e um equipo macro gotas $(5 \mathrm{~mL} / \mathrm{kg} / \mathrm{h})$. Também foi realizada tricotomia ampla na região do focinho.

Depois da indução anestésica, o paciente foi intubado, com sonda endotraqueal de $\mathrm{n}^{\circ} 10$ e mantido em sistema semiaberto. $\mathrm{O}$ monitor multiparamétrico foi conectado ao paciente, para avaliação do eletrocardiograma, pressão arterial invasiva (PAI), fração expirada de oxigênio (ETCO2), saturação parcial de oxigênio (SPO2) e temperatura.

A abertura do retalho foi calculada de modo que compreendesse três vezes a distância entre o centro da espinha escapular à borda cranial da escápula, e seu comprimento calculado a partir da mensuração do comprimento do defeito acrescido de três centímetros para o pivoteamento (Figura 2). A primeira incisão foi realizada sobre aespinha escapular e a segunda paralela a esta, compreendendo a largura já pré-determinada. Realizou-se a transposição e acomodamento do retalho sobre o defeito cirúrgico e a síntese do mesmo à área receptora foi realizada com padrão de sutura simples interrompido (Figura 3), assim como a aproximação do sítio doador em Y- plastia.

Após a cirurgia, uma bandagem compressiva e confecção de um colar cervical foram realizadas a fim de minimizar a dor, produção de seroma pós-operatório e promover a aderência do retalho ao sítio receptor. 
O tratamento pós-operatório foi realizado com Agemoxi (1,4 ml/SC, 1 x 20 dias), dexium (1,4 ml/SC, 1 x 20 dias), dipirona (1/2 comp/oral, 2 x 20 dias), além do uso tópico de solução bucal a base de clorexidine $0,12 \%$ e aplicação de acetonida de triancinolona em pomada orabase à cada 12 horas na sutura em mucosa oral.

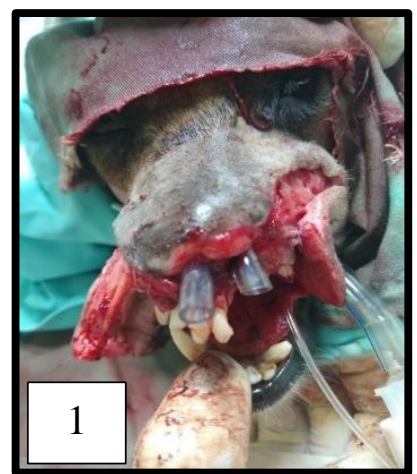

Figura 1. Face extensa com perda parcial de ossos nasais e ponte nasal e perda total do focinho

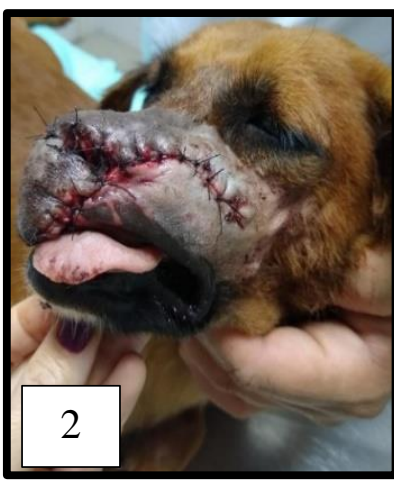

Figura 2. Abertura do retalho e início do procedimento cirúrgico

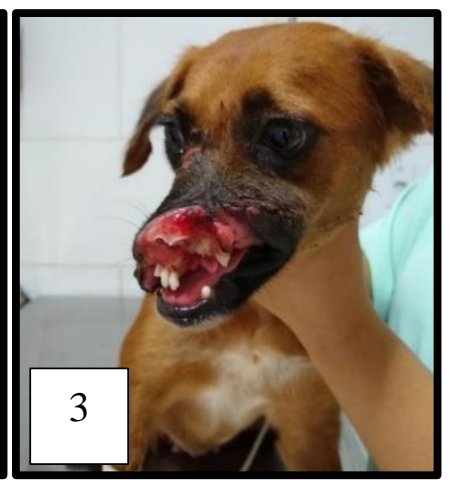

Figura 3. Face do paciente pós o procedimento cirúrgico.

Foram realizadas apenas duas limpezas no local durante este período,necessitando de anestesia para o procedimento, assim como para a retirada dos pontos, que foram retirados com 14 dias, o animal não apresentou complicação pós-cirúrgica. Percebe-se na Figura 4 a evolução do animal após a retirada dos pontos e cicatrização, o qual o procedimento inferi de forma direta no bem estar animal e com isso o ganho de peso e melhor qualidade de vida.

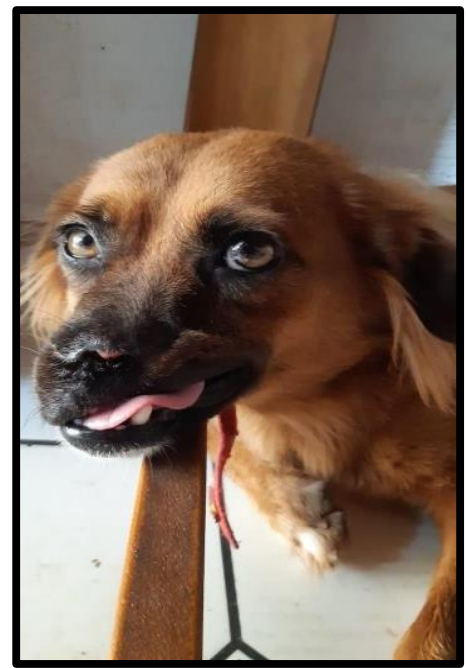

Figura 4. face do animal atual, depois da retirada dos pontos e cicatriz.

\section{Discussão}

O objetivo da cirurgia reconstrutiva é de restaurar a anatomia local, corrigindo as disfunções ou perdas, quer sejam sensitivas e/ou motoras, por meio da utilização de retalhos, enxertos e/ou biomateriais (Angeli et al., 2006; Scheffer et al., 2013). São comumente realizadas na síntese de defeitos secundários ao trauma, na correção ou melhora de anomalias congênitas ou após a remoção de neoplasmas (MacPhail, 2014; Oliveira et al., 2021).

Ao se tratar de cuidados após cirurgia plástica reparadora, é preciso levar em consideração importantes fatores que irão contribuir para a permanência do enxerto e também do retalho. Atuando na prevenção das complicações mais frequentes que são: formação de seroma, deiscência de pontos, contaminação bacteriana e desenvolvimento de necrose (Angeli et al., 2006).

Para a prevenção é necessária à administração de antibióticos, que devem ter início antes da cirurgia 
e ser estendida até a remoção dos pontos, tendo uma duração de 7 a 14 dias; fazendo o controle da inflamação e da dor. Da mesma forma, com início no pré-operatório, foram administrados antiinflamatórios não esteroidais como carprofeno, meloxicam, bem como derivados de opioides à base de tramadol e fentanil, e alguns anestésicos locais como bupivacaína e lidocaína, que podem ser administrados por um dreno para o alívio da dor (Kirpensteijn \& Ter Haar, 2019; Krahwinkel \& Boothe, 2006).

Além de fazer a administração de fármacos para controlar a dor, o animaltambém precisa ser contido nos momentos da troca de curativo, de forma que o local seja mobilizado no enxerto para não prejudicar o tratamento e por último e não menos importante, manter diariamente o animal com o colar elisabetano até a retirada dos pontos a fim de evitar lambeduras indesejáveis (Friend, 2009; Ladlow, 2009; Scheffer et al., 2013; White, 1999).

Quando não é feita a utilização da bandagem no pós-operatório pode causar o maior erro, que é a falha do enxerto ou retalho. Com várias e primordiais funções de prevenir as principais complicações já mencionadas, a bandagem não só previne à traumas sobre o local cirúrgico como também permite a união entre o leito doador e receptor e, em especial, a revascularização da peça enxertada (Campbell, 2006; Friend, 2009; Ladlow, 2009; Scheffer et al., 2013; Slatter, 2007; White, 1999).

\section{Conclusão}

O retalho de padrão axial omocervical se mostrou um modelo excelente para reconstrução de grandes defeitos em região de face lateral. O planejamento cirúrgico, a conduta transoperatória e o manejo pósoperatório instituído contribuíram para um pós-operatório de sucesso, com uma boa recuperação do paciente e sem complicações, sendo atualmente um animal saudável.

\section{Referências bibliográficas}

Angeli, A. L., Brandão, C. V. S., \& Freitas, R. S. (2006). Cirurgia reconstrutiva: retalhos cutâneos em pequenos animais. MEDVEP. Revista Científica de Medicina e Veterinária, 4(12), 87-95.

Campbell, B. G. (2006). Dressings, bandages, and splints for wound management in dogs and cats. Veterinary Clinics Small Animal Practice, 36, 759-791.

Coltro, P. S., Ferreira, M. C., Batista, B. P. S. N., Nakamoto, H. A., Milcheski, D. A., \& Tuma Júnior, P. (2011). Atuação da cirurgia plástica no tratamento de feridas complexas. Revista Do Colégio Brasileiro de Cirurgiões, 38(6), 381-386. https://doi.org/10.1590/s0100-69912011000600003.

Fossum, T. W. (2014). Cirurgia de pequenos animais (4th ed., Vol. 1). Elsevier Brasil.

Friend, E. (2009). Complications of wound healing. In J. Williams \& A. Moores (Eds.), BSAVA Manual of canine and feline wound management and reconstruction. British Small Animal Veterinary Association.

Kirpensteijn, J., \& Ter Haar, G. (2019). Reconstructive surgery and wound management of the dog and cat. Mason Publishing Company.

Krahwinkel, D. J., \& Boothe, H. W. (2006). Topical and systemic medications for wounds. Veterinary Clinics: Small Animal Practice, 36(4), 739-757.

Ladlow, J. (2009). Surgical drains in wound management and reconstructive surgery. In J. Williams \& A. Moore (Eds.), Manual of canine and feline wound management and reconstruction (pp. 15-24). British Small Animal Veterinary Association.

Leite, L. C. (2012). Ocorrência de endoparasitas com potencial zoonótico de transmissão em fezes de gatos (Felis catus domesticus Linnaeus, 1758) domiciliados na área urbana e região metropolitana de Castro-Paraná-Brasil. AMBIÊNCIA, 8(3), 923-930.

Macphail, C. M. (2014). Surgery of the integumentary system. In T. W. Fossum (Ed.), Small animal surgery. Elsevier Editora.

MacPhail, C. M. (2014). Cirurgia do sistema tegumentar. In Cirurgia de pequenos animais. Elsevier Rio de Janeiro.

Oliveira, T. S., Amancio, H. O., \& Faria, P. C. (2021). Retalho de padrão axial da artéria angular da 
boca para reconstrução plástica labial em cão: Relato de caso. PUBVET, 15(11), 1-4.

Scheffer, J. P., Atallah, F. A., Gomes, C., Estupñan, O. F. T., Silva, S. J. Q., Silva, T. I. R., Vale, D. F., \& Oliveira, A. L. A. (2013). Cirurgia reconstrutiva no tratamento de feridas traumáticas em pequenos animais. Brazilian Journal of Veterinary Medicine, 35(Supl. 1), 70-78.

Slatter, D. H. (2007). Manual de cirurgia de pequenos animais (Vol. 2). Manole São Paulo.

White, R. A. (1999). The etiology and classification of wounds and skin deficits. In D. Fowler \& J. M. Williams (Eds.), BSAVA Manual of canine and feline wound management and reconstruction. British Small Animal Veterinary Association.

Histórico do artigo:

Recebido: 28 de setembro de 2021

Aprovado: 4 de novembro de 2021

Disponível online: 29 de janeiro de 2022
Licenciamento: Este artigo é publicado na modalidade Acesso Aberto sob a licença Creative Commons Atribuição 4.0 (CC-BY 4.0), a qual permite uso irrestrito, distribuição, reprodução em qualquer meio, desde que o autor e a fonte sejam devidamente creditados. 